\title{
CONTROLE ALTERNATIVO DE Colletotrichum acutatum, AGENTE CAUSAL DA QUEDA PREMATURA DOS FRUTOS CÍTRICOS ${ }^{1}$
}

\author{
KATIA CRISTINA KUPPER ${ }^{2}$, JOSÉ ANTONIO MIRANDA BELLOTTE ${ }^{3}$, ANTONIO DE GOES $^{4}$
}

RESUMO - A queda prematura dos frutos cítricos (QPFC), causada por Colletotrichum acutatum, dados os grandes prejuízos que têm causado aos produtores, constitui-se numa doença de grande importância econômica. O controle da doença é feito predominantemente mediante uso de fungicidas, que eleva o custo de produção e afeta negativamente o meio ambiente. Diante disso, este trabalho teve por objetivo buscar um método alternativo de controle da QPFC, mediante o uso de agentes de biocontrole ou de biofertilizantes. Diferentes concentrações de biofertilizantes (originários de duas fontes distintas e denominados de Biol e Bio 2); três isolados de Bacillus subtilis (ACB-69; 72 e 77) e três isolados de Trichoderma spp. (ACB-14; 37 e 39) foram testados, isoladamente ou em combinação, sob condições de laboratório, quanto à capacidade inibitória da germinação de conídios de C. acutatum. Estudaram-se, ainda, a produção de metabólitos termoestáveis por $B$. subtilis e o efeito sobre a germinação do patógeno. Quinze isolados de B. subtilis foram testados quanto à capacidade de prevenir a infecção por C. acutatum em flores destacadas de limaácida 'Tahiti' e, no campo, foram instalados dois experimentos, visando a testar ACBs e biofertilizantes no controle da doença. Verificou-se que o isolado ACB-72 (B. subtilis) e ACB-37 (T. pseudokoningii) foram os que mais inibiram a germinação do patógeno. Quanto à produção de metabólitos termoestáveis, ACB-69 e 77 foram os mais eficientes em produzir substâncias antifúngicas, e em quantidades suficientes para inibirem a germinação do patógeno. A mistura dos quatro isolados de Bacillus (ACBs: 69; 72; 77 e AP3) foi o que apresentou maior porcentagem de inibição (73\%). Os biofertilizantes (Bio1 e Bio2), em concentrações acima de $10 \%$ e, quando em associação com isolados de Trichoderma spp., promoveram maiores inibições na germinação de C. acutatum. Em testes com flores destacadas, verificou-se que, onde foram aplicados os ACBs 69; 76; 74 e 77, as porcentagens de pétalas sem sintomas de infecção por C. acutatum foram de 83; 92; 92 e $97 \%$, respectivamente. Mediante avaliações a campo, verificou-se a potencialidade de B. subtilis e de biofertilizantes em controlar a doença.

Termos para indexação: Bacillus subtilis, Trichoderma spp., biofertilizante

\section{ALTERNATIVE CONTROL OF Colletotrichum acutatum, CAUSAL AGENT OF POSTBLOOM FRUIT DROP OF CITRUS}

\begin{abstract}
Postbloom Fruit Drop of Citrus (PDF), caused by Colletotrichum acutatum, has caused losses to citrus producers and therefore it is economically very important. This disease is generally controlled by fungicide sprayings, which increase the production cost, and affects the environment. Thus, this work aimed at developing an alternative control method through the use of biocontrol agents, or biofertilizers. Different concentrations of biofertilizers (from two distinct sources and named Bio1 and Bio2), three strains of Bacillus subitlis (BCA-69, 72 and 77) and three isolates of Trichoderma spp. (BCA-14, 37 and 39) were tested, in vitro, alone or in combination, for the inhibitory capacity of conidia germination of C. acutatum. It was studied the production of thermo-stable metabolites by $B$. subtilis and their effect on the germination of $C$. acutatum conidia. Under in vivo conditions, 15 isolates of $B$. subtilis were tested for the ability to prevent $C$. acutatum infection on 'Tahiti' lime detached flowers and in the field, where two experiments were installed, for testing the BCA and biofertilizers in the control of the disease. It was found that the isolate BCA-72 (B. subtilis) and BCA-37 (T. pseudokoningii) were the most efficient in inhibiting conidia germination. BCA69 and BCA-77 were the most effective in producing anti-fungal substances, and in quantities sufficient to inhibit the germination of C. acutatum. The mixture of four strains of Bacillus (BCA: 69, 72, 77 and AP3) presented the highest percentage of inhibition (73\%). Regarding the use of biofertilizers (Bio1 and Bio2), it was observed that concentrations above $10 \%$ of the product, when combined with the strains of Trichoderma spp. decreased the pathogen germination. The experiments with detached flowers showed that the flowers where the BCA: 69, 76, 74 and 77 were applied presented 83, 92, 92 and 97\% respectively, of the petals without symptoms of infection by $C$. acutatum. Field tests showed the potential of $B$. subtilis and biofertilizers in controlling the disease.
\end{abstract}

Index terms: Bacillus subtilis, Trichoderma spp., biofertilizer.

\footnotetext{
'(Trabalho 287-08). Recebido em: 19-11-2008. Aceito para publicação em: 18-11-2009.

${ }^{2}$ Dra. e Pesquisadora Científica. Centro APTA Citros Sylvio Moreira, Instituto Agronômico, Av. Anhanguera, km 158, CEP 13490970, Cordeirópolis-SP. - katia@centrodecitricultura.br

${ }^{3}$ Engenheiro Agronômo. Louis Dreyfus Commodities Agroindustrial Ltda., Estrada de Botucatu-Itatinga, km12, São Paulo.

${ }^{4}$ Dr. em Fitopatologia. Universidade Estadual Paulista, FCAV/UNESP, CEP 14884-900, Jaboticabal-SP. Bolsista CNPq.
} 


\section{INTRODUÇÃO}

O Estado de São Paulo detém 97\% das exportações brasileiras de suco de laranja, possuindo uma das maiores áreas citrícolas do mundo, com cerca de 200 milhões de pés de laranja em 13.000 propriedades. Tal área compreende cerca de $690 \mathrm{mil}$ ha distribuídos ao longo de quase todo o Estado de São Paulo, sendo complementado pelas áreas citrícolas localizadas no Triângulo Mineiro. Estima-se que, para a safra de 2007/2008, o setor tenha sido responsável pela produção de 368 milhões de caixas de 40,8 $\mathrm{kg}$. A atividade é geradora de aproximadamente 400 mil empregos, sendo de grande importância para o desenvolvimento agrícola do Estado (Secretaria de Estado de Agricultura, Pecuária e Abastecimento de São Paulo, 2008).

Não obstante a enorme importância que a atividade citrícola tem para a economia nacional, as plantas cítricas são acometidas por uma série de pragas e doenças, que são responsáveis por reduções consideráveis na produção e na qualidade das frutas, tornando-se, em muitos casos, fatores limitantes ao processo de produção.

Dentre essas doenças, pode-se destacar a "Queda Prematura dos Frutos Cítricos" (QPFC), descrita pela primeira vez em Belize, em 1979, como sendo causada pelo fungo Colletotrichum gloeosporioides Penz (Fagan, 1979), que foi reclassificado por Brown et al. (1996), como Colletotrichum acutatum Simmonds.

No Brasil, a doença foi relatada no Rio Grande do Sul (Dornelles, 1977) e, atualmente, está presente em todos os municípios de São Paulo, além de outros Estados, como Rio de Janeiro, Paraná, Bahia, Minas Gerais, Goiás e Amazonas. Condições que propiciam mais de uma florada, ou variedades que floresçam mais de uma vez por ano, favorecem a ocorrência da doença. Assim sendo, no Brasil, a doença é mais severa nos limões-verdadeiros, em lima-ácida 'Tahiti', no limão 'Galego' e na laranja 'Pera' (Feichtenberger, 1991).

A medida predominante de controle é a pulverização com produtos químicos na época da florada. No entanto, os custos financeiros e ambientais de tais aplicações, aliados às crescentes restrições à presença de resíduos, estão a exigir o estudo de novas alternativas. Entre estas, o controle biológico ou a utilização de extratos aquosos de matéria orgânica e biofertilizantes surgem como técnicas importantes que, além da sua coerência ecológica, em muitos casos, poderá constituir-se em tecnologia poupadora de capital.

Dentre os antagonistas mais estudados, encontram-se espécies de fungos do gênero Trichoderma (Dubos et al., 1982; Melo, 1998; Moretto et al., 2001) e a bactéria Bacillus subtilis, a qual vem destacando-se no controle de doenças do filoplano (Ferreira et al., 1991; Bettiol et al., 1994; Sonoda \& Guo, 1996; Kalita et al., 1996; Kupper \& Gimenes-Fernandes, 2002; Kupper et al., 2003). Segundo Arras \& Arru (1997), os mais importantes mecanismos de antagonismo incluem a antibiose, parasitismo, competição e indução de resistência. De modo geral, as bactérias antagonisticas (B. subtilis, Pseudomonas cepacia, P. fluorescens e outras) e os fungos, como, por exemplo, T. harzianum e outros, agem principalmente por antibiose e, ocasionalmente, por parasitismo e competição.

Extratos e biofertilizantes possuem uma complexa e elevada comunidade microbiana, com presença de bactérias, fungos leveduriformes e filamentosos e actinobactérias (Weltzien, 1989; Castro et al., 1992; Elad \& Shtienberg, 1994; McQuilken et al., 1994; Yohalem et al., 1996). O biofertilizante, produzido pela digestão anaeróbia de esterco bovino, vem sendo recomendado para o controle de diversas doenças, como aquelas causadas pelos fungos Colletotrichum gloeosporioides, C. orbiculare, Penicillium digitatum e Guignardia citricarpa (Castro et al., 1991; Zhang et al., 1996 e Kupper et al., 2006). Nesse contexto, este trabalho teve por objetivo estudar a possibilidade de se obter um método alternativo de controle da doença, por meio do uso de agentes de biocontrole ou de biofertilizantes sobre C. acutatum.

\section{MATERIAL E MÉTODOS}

Para a realização deste trabalho, os testes in vitro foram realizados no Laboratório de Fitopatologia do Departamento de Fitossanidade da Unesp - Câmpus de Jaboticabal, enquanto, o experimento sob condições de campo, com ocorrência natural da doença, foi realizado em propriedade da Agropecuária Guacho S.A., localizada no município de Santa Cruz do Rio Pardo - SP.

Os agentes de controle biológico (ACBs), Trichoderma spp. e Bacillus subtilis, foram isolados a partir de amostras de solo, de folhas e flores de citros retiradas de pomares de diferentes localidades do Estado de São Paulo (Moretto et al., 2001; Kupper \& Gimenes-Fernandes, 2002).

Os biofertilizantes utilizados foram produzidos em condições de fermentação anaérobia e aérobia, e designados neste trabalho como Biol e Bio 2, respectivamente. 
Efeito dos ACBs na germinação de $\boldsymbol{C}$. acutatum - Para esse estudo, suspensões de células bacterianas de culturas de dois dias de incubação ou dos fungos (com sete dias de incubação) foram obtidas de colônias ativas, retiradas de placas de Petri contendo meio de cultura batata dextrose ágar (BDA). Foram utilizados os seguintes tratamentos: ACB-69; ACB-72; ACB-77 (todos correspondentes a Bacillus subtilis); ACB-14; ACB-37; ACB-39 (Trichoderma viride, T. pseudokoningii e T. aureoviride, respectivamente); mistura dos isolados de Bacillus (ACBs 69+72+77); mistura dos isolados ACBs 37+69+14; mistura dos ACBs $69+37$ e testemunha.

Gotas de $10 \mu \mathrm{L}$ da suspensão da mistura ou de cada ACB (1 x $\left.10^{6} \mathrm{ufc} / \mathrm{mL}\right)$ e de suspensão de conídios do patógeno $\left(1 \times 10^{4}\right.$ esporos $\left./ \mathrm{mL}\right)$ foram depositadas em áreas demarcadas de lâminas, previamente preparadas, contendo meio ágar-água. Para o tratamento-testemunha, foram colocadas gotas de água destilada e esterilizada, ao invés dos ACBs. As lâminas, após montagem, foram colocadas no interior de placas de Petri esterilizadas, contendo um chumaço de algodão embebido em água destilada e esterilizada. As culturas foram incubadas em estufa para B.O.D., no escuro, a $25^{\circ} \mathrm{C}$, por 16 horas.

Após o tempo de incubação, adicionou-se uma gota contendo $10 \mu \mathrm{L}$ de solução de azul lático, nas áreas demarcadas da lâmina, com a finalidade de paralisar o desenvolvimento do patógeno. A seguir, procedeu-se a determinação do número de conídios germinados e não germinados. Para isto, foram avaliados 100 conídios, a partir dos quais estabeleceu-se a porcentagem de germinação. Foi considerado germinado o conídio cujo tamanho do tubo germinativo era maior ou igual à sua largura na região mediana. Utilizou-se o delineamento inteiramente casualizado, sendo cada tratamento composto por sete repetições. Os dados foram submetidos à análise de variância, e as médias dos tratamentos, comparadas pelo teste de Tukey, a 5\% de probabilidade.

Efeito de biofertilizantes na germinação de C. acutatum - Foram testados os biofertilizantes Bio1 e Bio 2 nas seguintes concentrações: $0 ; 1,0 ; 2,5 ; 5,0$; 10,0 e $20,0 \%$. O biofertilizante Bio1 foi produzido de acordo com Bettiol et al. (1998), sob condições anaeróbias, utilizando esterco bovino suplementado com micronutrientes e aditivos para estimular a fermentação $\left(0,65 \%\right.$ de $\mathrm{N} ; 680 \mu \mathrm{g} / \mathrm{mL}$ de $\mathrm{P}_{2} \mathrm{O}_{5 ;} 0,25 \%$ de $\mathrm{K}_{2} \mathrm{O} ; 975 \mu \mathrm{g} / \mathrm{mL}$ de $\mathrm{Ca} ; 660 \mu \mathrm{g} / \mathrm{mL}$ de $\mathrm{Mg} ; 0,70 \%$ de S; 0,18\% de Fe; $490 \mu \mathrm{g} / \mathrm{mL}$ de $\mathrm{Mn} ; 290 \mu \mathrm{g} / \mathrm{mL}$ de $\mathrm{Cu} ; 0,29 \%$ de $\mathrm{Zn} ; 350 \mu \mathrm{g} / \mathrm{mL}$ de $\mathrm{B} ; 0,12 \%$ de Na; $270 \%$ de matéria orgânica; densidade $1,01 \mathrm{~g} / \mathrm{mL}$; relação $\mathrm{C} / \mathrm{N}: 2 / 1$ e pH 3,7). O biofertilizante Bio 2 foi produzido, sob condições aeróbias, misturando-se 50 kg de Microgeo ${ }^{\circledR}$ mais 200 litros de esterco de gado, completando-se o volume com água para 1.000 litros, sob agitação. Utilizou-se para a condução do ensaio a mesma metodologia descrita para o ensaio anterior, sendo que, em vez dos ACBs, foram utilizadas as diferentes concentrações dos biofertilizantes. A avaliação e o delineamento experimental foram realizados de acordo com o descrito no ensaio anterior, cujos dados obtidos quanto ao efeito das diferentes concentrações dos biofertilizantes foram submetidas à análise de regressão.

Efeito de isolados de B. subtilis e Trichoderma spp. combinados com biofertilizante na germinação de C. acutatum - Os antagonistas utilizados neste experimento foram os que apresentaram os melhores resultados no primeiro ensaio, sendo eles: ACB-14, ACB-37, ACB-72 e ACB-77. Os tratamentos avaliados foram: 1) Testemunha; 2) $\mathrm{ACB} 14+\mathrm{Bio} 1$; 3$) \mathrm{ACB} 37+\mathrm{Bio} 1$; 4) $\mathrm{ACB}$ $72+\mathrm{Bio1}$; 5) $\mathrm{ACB} 77+\mathrm{Bio1}$; 6) $\mathrm{ACB} 14+$ Bio2; 7) ACB $37+$ Bio2; 8) ACB72 + Bio2; 9) $\mathrm{ACB} 77$ + Bio2; 10) Bio1, e 11) Bio2.

Seguindo os mesmos procedimentos dos ensaios anteriores, para cada tratamento, gotas de $10 \mu \mathrm{L}$ de $\mathrm{ACB}$ e da suspensão de esporos do patógeno, nas mesmas concentrações já descritas e, ainda, do biofertilizante sem diluição, foram depositadas em áreas demarcadas, em lâminas previamente preparadas, contendo meio ágar-água. Para o tratamento-testemunha, foram colocadas gotas de água destilada e esterilizada, em vez dos ACBs e dos biofertilizantes.

A incubação das culturas, a avaliação, o delineamento experimental e as análises estatísticas foram realizados de acordo com o descrito no primeiro ensaio.

Efeito de metabólitos termoestáveis, produzidos por Bacillus subtilis, na germinação de C. acutatum - Para a produção dos metabólitos dos ACBs, foram utilizadas colônias de quatro isolados de B. subtilis (ACB-69; 72; 77 e AP3). Erlenmeyers com capacidade para $250 \mathrm{~mL}$, contendo $50 \mathrm{~mL}$ de meio batata-dextrose (BD), contendo três discos de meio com crescimento de $B$. subtilis, foram incubados em condições ambiente de laboratório por sete dias, no escuro, e sob agitação mecânica. Em seguida, uma alíquota de $40 \mathrm{~mL}$ foi retirada de cada frasco, correspondente a cada isolado de B. subtilis, submetida à centrifugação $(7379 \mathrm{~g}) \mathrm{e}$, posteriormente, à autoclavagem $\left(120^{\circ} \mathrm{C}\right.$ e $1 \mathrm{~atm}$ de pressão), por 20 minutos.

Para testar o efeito dos metabólitos termo- 
estáveis na germinação do fitopatógeno, alíquotas de $10 \mu \mathrm{L}$ dos produtos provenientes de cada um dos antagonistas, isolados ou em combinação, foram depositadas simultaneamente com $10 \mu \mathrm{L}$ de uma suspensão do fitopatógeno ( 1 x $10^{4}$ conídios $\left./ \mathrm{mL}\right)$, em áreas demarcadas em lâminas contendo meio ágarágua. $\mathrm{O}$ tratamento-testemunha constituiu-se apenas da suspensão do patógeno com BD autoclavado.

As culturas foram incubadas em estufa para B.O.D. a $25^{\circ} \mathrm{C}$, no escuro, por $16 \mathrm{~h}$. Os tratamentos avaliados foram: 1)Testemunha; 2)ACB-72; 3)ACB$69+\mathrm{ACB}-\mathrm{AP} 3$; 4)ACB-72 + ACB-AP3 ; 5)ACB-69 + ACB-72; 6) Mistura dos antagônicos; 7)ACB-69; 8) ACB-77; 9)ACB-69 + ACB-77; 10)ACB-72 + ACB-77 e 11)ACB-AP3. A avaliação, o delineamento experimental e as análises estatísticas foram similares às descritas nos ensaios anteriores.

Eficiência de Bacillus subtilis no controle de $C$. acutatum em flores destacadas de lima-ácida 'Tahiti'- Onze isolados de B. subtilis descritos por Kupper \& Gimenes-Fernandes (2002), juntamente com os já descritos neste trabalho (ACBs: 69, 70, 72 e 77), foram testados em flores destacadas quanto à capacidade de prevenir a infecção por $C$. acutatum.

Para a produção do caldo fermentado, colônias dos agentes de biocontrole foram repicadas para Erlenmeyers com capacidade para $500 \mathrm{~mL}$, contendo $100 \mathrm{~mL}$ de BD. Em seguida, cada frasco, com o respectivo $\mathrm{ACB}$, foi mantido sob agitação constante, em agitador mecânico, por cinco dias ,em condições ambiente de laboratório.

Flores destacadas de lima-ácida 'Tahiti' foram colocadas em caixas Gerbox ${ }^{\circledR}$, com os pedúnculos inseridos em orifícios efetuados em espuma sintética de $0,5 \mathrm{~cm}$ de espessura, que se encontrava sobre papel de filtro umedecido com água destilada e esterilizada. Em seguida, as caixas Gerbox ${ }^{\circledR}$ contendo as flores foram colocadas por vinte minutos, distantes $70 \mathrm{~cm}$ abaixo de duas lâmpadas germicidas Sankyo Denki ${ }^{\circledR}$ G30T8, de 30 watts, antes da aplicação dos ACBs e inoculação do fitopatógeno. Foi testado o efeito da aplicação do caldo fermentado 24 horas antes da inoculação do patógeno $\left(1 \times 10^{3}\right.$ conídios $/ \mathrm{mL})$. As testemunhas inoculadas e não inoculadas foram constituídas de flores em que se colocaram apenas gotas de suspensão de conídios de C. acutatum ou de água destilada e esterilizada, respectivamente.

Para aplicação dos ACBs e inoculação do patógeno, utilizou-se uma seringa com agulha de injeção, de modo a depositar sobre cada pétala uma gota $(10 \mu \mathrm{L})$ do caldo fermentado $\left(1 \times 10^{7} \mathrm{ufc} / \mathrm{mL}\right)$ de cada ACB e, posteriormente, a mesma quantidade da suspensão do fungo. Após a inoculação, efetuou-se a incubação em estufa para B.O.D. (12 horas de luz e 12 horas de escuro, a $24^{\circ} \mathrm{C} \pm 2$ ).

A avaliação foi realizada 72 horas após a inoculação, determinando-se a porcentagem de pétalas com sintomas. Foi utilizado o delineamento casualizado, com três repetições, sendo que cada repetição foi representada por uma caixa Gerbox ${ }^{\circledR}$ com dez flores. Os dados foram submetidos à análise de variância, e as médias dos tratamentos, comparadas pelo teste de Tukey, a 5\% de probabilidade.

Eficiência de Bacillus subtilis e de biofertilizantes no controle de Colletotrichum acutatum sob condições de campo - $\mathrm{O}$ experimento constituiu-se de dois ensaios conduzidos consecutivamente, nas safras de 2000-2001 e 2001-2002, em pomar de laranjeira da variedade 'Pera-Rio', enxertada sobre 'Cleópatra', com 12 anos de idade. No Ensaio 1, foram utilizados os tratamentos: ACB-69 (B. subtilis), Bio 2 e testemunha (sem aplicação), enquanto, no Ensaio 2, os tratamentos foram: 1) Biopiro ${ }^{\circledR}$; 2) Bio $2+\mathrm{ACB}-14 ; 3$ ) ACB-72;4) ACB- 69; 5) Bio 2; 6) Bio1; 7) ACB-37; 8) Bio 2 + ACB 37; 9) Mistura (ACBs 69+72+77), e 10) Testemunha. Para a obtenção da suspensão dos antagonistas, colônias do ACB foram repicadas para Erlemmeyers ( 2 frascos) com capacidade para $1.000 \mathrm{~mL}$, contendo $300 \mathrm{~mL}$ de meio BD. Em seguida, procedeu-se a incubação, em condições ambiente de laboratório, sob agitação constante, em agitador mecânico, por 13 dias, no escuro.

Foram realizadas duas aplicações de cada tratamento, durante a época do florescimento. A primeira aplicação deu-se quando as flores estavam no estádio de "cabeça-de-fósforo", caracterizado pela predominância de botões florais verdes, a verdeesbranquiçados, e a segunda no estádio de "cotonete", onde predominavam botões florais brancos, fechados, alongados ou em expansão.

Os antagonistas $\left(1 \times 10^{8}\right.$ células $\left./ \mathrm{mL}\right)$ e os biofertilizantes (a 10\%) foram aplicados por meio de pulverizador tratorizado, equipado com pistolas, com capacidade para 400L, sendo aplicado o volume de calda suficiente para atingir o ponto de escorrimento.

Utilizou-se o delineamento experimental de blocos ao acaso, com cinco repetições, sendo que cada parcela experimental foi constituída por uma planta. A avaliação foi realizada cerca de 90 dias após a primeira aplicação do antagonista e do biofertilizante, efetuando-se a contagem do número de frutos vingados e do número de cálices retidos e/ou 
amarelecidos devido à doença, a partir dos quais se obteve o número médio de frutos efetivos (NMFE), segundo Goes (1995).

\section{RESULTADOS E DISCUSSÃO} acutatum

\section{Efeito dos ACBs na germinação de $C$.}

Verificou-se que, com exceção dos ACBs 69 e 39, os demais agentes de controle biológico afetaram a germinação do fitopatógeno, sendo que os ACBs 37; 72; 77 e 14 inibiram a germinação em torno de $81 ; 62 ; 56$ e 54\%, respectivamente, em relação à testemunha (Tabela 1). Observou-se, ainda, que a mistura dos ACBs não resultou em aumento significativo da eficiência dos antagonistas sobre a inibição da germinação do fungo, embora os tratamentos que envolveram a mistura dos isolados tenham diferido da testemunha, com inibições na germinação dos conídios de C. acutatum, que variaram de 43 a 52\%.

Os dados obtidos mostram-se convergentes aos descritos por Ferreira et al. (1991), os quais verificaram que um isolado de $B$. subtilis, obtido a partir de troncos da videira, afetou a germinação in vitro de Eutypa lata, agente causal do declínio da videira. De acordo com os autores, $B$. subtilis causou $100 \%$ de inibição na germinação de ascósporos deste fitopatógeno.

Bettiol \& Várzea (1992) observaram que suspensões de células de dois isolados de $B$. subtilis (AP-3 e AP-150), em concentrações superiores a 5 x $10^{7} \mathrm{ufc} / \mathrm{mL}$, inibiram a germinação de uredinósporos de diferentes raças de Hemileia vastatrix, demonstrando-se eficientes no seu controle, quando em condições de casa de vegetação. Em outro estudo, sobre o efeito de dois isolados de $B$. subtilis sobre a germinação de C. acutatum, agente causal da florpreta do morangueiro, Costa (2001) verificou que os ACBs inibiram a germinação de conídios do patógeno e foram capazes de produzir metabólitos tóxicos em quantidades suficientes para inibir o desenvolvimento do fungo. Segundo o autor, o principal mecanismo de ação envolvido no controle de $C$. acutatum por $B$. subtilis foi o da antibiose.

\section{Efeito de biofertilizantes na germinação de $C$. acutatum}

Verificou-se que os dois biofertilizantes, nas concentrações entre 1 e $20 \%$, inibiram significativamente a germinação dos conídios do fitopatógeno, com destaque para o Bio 2, que apresentou as maiores porcentagens de inibições (Figura 1).

Estes resultados mostram-se, ainda que parciais, compatíveis aos obtidos por Tratch \& Bettiol
(1997), que estudaram o efeito de biofertilizante sobre a germinação de conídios de diversos fungos. Segundo tais investigadores, biofertilizante em concentrações acima de $20 \%$ inibiram completamente a germinação de conídios de Botritys cinerea e, quando superior a $10 \%$, a de conídios de Alternaria solani. No presente estudo, observou-se que tanto Bio 1 como Bio 2, nas concentrações de 10 e $20 \%$, respectivamente, inibiram a germinação de C. $a c u-$ tatum em níveis superiores a 50\%.

Efeito de isolados de B. subtilis e Trichoderma spp. combinados com biofertilizantes na germinação de $\boldsymbol{C}$. acutatum

Os biofertilizantes, isoladamente ou em combinação com $\mathrm{ACBs}$, diferiram significativamente da testemunha (Tabela 02), destacando-se os tratamentos Bio 2, ACB-37+Bio 2 e ACB-14+Bio 2; ou Bio1, isoladamente ou em combinação com ACB14 ou ACB-37, com maior inibição da germinação conidial do patógeno. As porcentagens de inibição da germinação de conídios de C. acutatum, em relação à testemunha, variaram de 73 a $84 \%$.

Os agentes de biocontrole ACB-72 e ACB-77 foram eficientes quanto à inibição da germinação de conídios de C. acutatum (Tabela 1). Entretanto, quando tais agentes foram avaliados em mistura com biofertilizantes, essa eficiência mostrou-se reduzida (Tabela 2). Por outro lado, os biofertilizantes Bio1 e Bio 2, empregados isoladamente, promoveram redução da germinação conidial de C. acutatum, com indicação de que esses, mesmo isoladamente, mostram-se promissores no controle da QPFC, sob condições naturais de infecção. A redução dos percentuais de eficiência dos $\mathrm{ACBs}$, quando em combinação com os biofertilizantes, aparentemente, deve-se às substâncias existentes nos biofertilizantes, as quais, dada a sua complexidade, podem ter afetado a atividade biocontroladora dos ACBs.

Efeito de metabólitos termoestáveis, produzidos por $B$. subtilis, na germinação de $C$. acutatum

Dentre os agentes de controle avaliados, apenas o ACB-72 não produziu metabólitos tóxicos termoestáveis, em quantidades suficientes para inibir a germinação de C. acutatum, não diferindo estatisticamente do tratamento-testemunha (Tabela 3). Os demais agentes, isoladamente ou em mistura, foram eficientes na produção de substâncias antimicrobianas, cujas porcentagens de inibições variaram de 35 a $73 \%$. Dentre os tratamentos, o correspondente à combinação dos quatro isolados de $B$. subtilis foi o mais eficiente, apresentando maior inibição na ger- 
minação dos conídios do patógeno (Tabela 3).

Com relação ao comportamento individual dos isolados de ACBs, observou-se atividade antagonística diferenciada, notadamente quanto à germinação dos conídios de C. acutatum, não obstante sejam os mesmos de uma mesma espécie (Tabelas $1 \mathrm{e}$ 3). O ACB-72 (Tabela 1), quando aplicado em forma de suspensão de células bacterianas, foi o que mais inibiu a germinação do fungo, enquanto ACB-69 foi o menos eficiente dentre os tratamentos, embora tenha diferido do tratamento-testemunha. Quanto à produção de substâncias antifúngicas pelas bactérias, notou-se que ACB-72 foi o menos eficiente, enquanto ACB-69 se mostrou como o mais eficiente. Tais resultados sugerem que o modo de ação de ACB-72 deve dar-se mais por competição, enquanto, no caso de ACB-69, o seja por antibiose, como já observado por Kupper et al. (2003).

O bom desempenho do efeito dos filtrados dos ACBs, apresentado no presente trabalho, mostra-se coerente com o obtido por outros investigadores (Cubeta et al.,1985; Bettiol \& Kimati, 1990; Kupper et al., 2003), os quais demonstraram que metabólitos tóxicos, originários de colônias de Bacillus spp., inibiram o crescimento de colônias de várias espécies de fungos fitpopatogênicos. Bettiol \& Kimati (1989), inclusive, em suas pesquisas, observaram a ocorrência de grande número de microrganismos antagônicos a Pyricularia oryzae Cavana, com destaque à espécie $B$. subtilis, cujo mecanismo de ação, segundo os autores, foi o da antibiose.

Eficiência de $B$. subtilis no controle de C. acutatum em flores destacadas de lima-ácida 'Tahiti'

Nove, dentre os 15 isolados B. subtilis aplicados sobre flores destacadas de lima-ácida 'Tahiti', 24 horas antes da inoculação de C. acutatum, mostraram bom efeito protetor, diferindo estatisticamente da testemunha, cujos índices de controle variaram de $44 \%$ a $97 \%$ (Tabela 4). Entretanto, dentre tais isolados, os que sobressaíram foram ACBs 69; 76; 74 e 77, os quais apresentaram maior número de pétalas sadias, cujos índices de pétalas assintomáticas foram de 83; 92; 92 e 97\%, respectivamente. A eficiência destes ACBs mostra-se convergente aos resultados obtidos por Kupper \& Gimenes-Fernandes (2002), quando flores destacadas de lima-ácida 'Tahiti' foram tratadas com os antagonistas, simultaneamente à inoculação do patógeno, mostrando bom efeito curativo de C. acutatum. De acordo com os autores, com exceção do ACB-77, os demais antagonistas proporcionaram porcentagens de controle acima de 95\%, e agiram principalmente por antibiose. Quando da aplicação simultânea de ACBs, acompanhado de inoculação de C. acutatum, há, também, a possibilidade da produção de compostos antimicrobianos, cuja eficiência não pode ser descartada. Os demais antagonistas testados no presente trabalho (ACBs $63 ; 64 ; 75 ; 71 ; 65 ; 70 ; 72 ; 73 ; 67 ; 66$ e 86) apresentaram eficiência que variou de $1,5 \%$ a $79 \%$ (Tabela 4). Entretanto, quando esses mesmos isolados foram aplicados simultaneamente à inoculação do patógeno, sua eficiência de controle foi superior a 90\% (Kupper \& Gimenes-Fernandes, 2002). Tais resultados constituem-se em indicações de que os agentes de biocontrole, testados, agem mais positivamente de maneira curativa, em detrimento do controle preventivo de C. acutatum.

\section{Eficiência de B. subtilis e de biofertilizan- tes no controle de Colletotrichum acutatum sob} condições de campo

O emprego do antagonista ACB-69, assim como o emprego de biofertilizante foram eficientes no controle da doença, diferindo estatisticamente da testemunha (Tabela 5). Observou-se que, com o emprego de tais tratamentos, eles proporcionaram retenções de frutos em níveis superiores a 100\%, quando comparado à testemunha. No caso particular do ACB-69, dados semelhantes comprovando a eficiência do antagonista foram relatados por Kupper et al. (2003). Segundo os autores, o respectivo isolado de B. subtilis, quando aplicado para controle da doença, redundou em menor porcentagem de flores com sintomas e maior número médio de frutos efetivos, e não diferiu estatisticamente do fungicida benomyl (tratamento-padrão de referência).

Vários trabalhos na literatura têm demonstrado a viabilidade do emprego de isolados de $B$. subtilis para o controle de doenças da parte aérea de citros (Sonoda \& Guo, 1996; Kalita et al., 1996; Kupper \& Gimenes-Fernandes, 2002; Kupper et al., 2003). Em outras culturas, Baker et al. (1983) verificaram que a severidade da ferrugem do feijoeiro foi reduzida em, pelo menos, 75\%, em 1982 e 1983, com três aplicações por semana de B. subtilis, apresentando o mesmo nível de controle, quando comparado ao fungicida mancozeb, aplicado uma vez por semana. Korsten et al. (1997) relataram que aplicações pré-colheita com a bactéria, isoladamente ou integrada com fungicidas, em especial oxicloreto de cobre, reduziram efetivamente, em condições de campo, infecções naturais de Pseudocercospora purpurea em abacateiros.

Com relação aos dados do Ensaio 2, verificou-se que o biofertilizante BioPiro ${ }^{\circledR}$ foi o que 
contribuiu para maior quantidade de números de frutos efetivos, quando comparado ao tratamentotestemunha (Tabela 6).

Embora a quantidade de doença não tenha sido suficientemente alta para mostrar com maior nitidez a eficiência dos tratamentos, os agentes de controle biológico e os biofertilizantes utilizados, isoladamente ou em combinação com os antagonistas, apresentaram potencial para o controle da QPFC, com exceção dos tratamentos Bio 2+ACB-37 e a mistura dos isolados de $B$. subtilis, os quais não diferiram da testemunha.

A eficiência dos biofertilizantes pode estar ligada à sua composição química e microbiológica, apresentando efeito inibitório sobre a germinação de vários fungos fitopatogênicos, como observado por Tratch \& Bettiol (1997). Como a comunidade microbiana existente no biofertilizante é rica e diversa, acredita-se que todos os mecanismos de ação dos microrganismos sobre o patógeno possam ocorrer simultaneamente, com reflexos positivos na supressão da atividade dos patógenos. Tal alternativa de controle é viável e desejável, quando comparada com o controle tradicional, principalmente por não deixar resíduo tóxico sobre os frutos cítricos. Essa importância mostra-se ainda mais evidente para o caso de variedades que apresentam vários surtos de floração, com coexistência de frutos próximos à colheita e flores, simultaneamente, como em diferentes variedades de laranjas-doces, especialmente Pera, Valência e Natal.
Para o caso de pomares localizados em regiões cujo florescimento se estende por 60 a 80 dias, como às vezes ocorre no sul do Estado de São Paulo, esta alternativa de controle poderá contribuir para minimizar o número de pulverizações visando ao controle da doença.

O emprego do biofertilizante para controle de doença em citros foi relatado por Kupper et al. (2006). De acordo com os autores, o biofertilizante, produzido pela digestão anaeróbia do esterco de gado, apresentou potencial para o controle de Guignardia citricarpa, agente causal da mancha-preta dos frutos cítricos.

$\mathrm{O}$ uso de microrganismos antagonistas, bem como o de biofertilizantes, pode ser uma estratégia promissora para o controle de C. acutatum, como foi demonstrado em ensaios de laboratório e de campo, justificando-se a realização de estudos complementares para definir melhores concentrações e épocas de aplicações destes produtos alternativos. Diante da potencialidade de controle da doença, mediante o emprego de BioPiro ${ }^{\circledR}$ (Tabela 6), sob condições de campo, a realização de estudos in vitro faz-se necessária, na tentativa de entender o seu mecanismo de ação sobre o fitopatógeno.

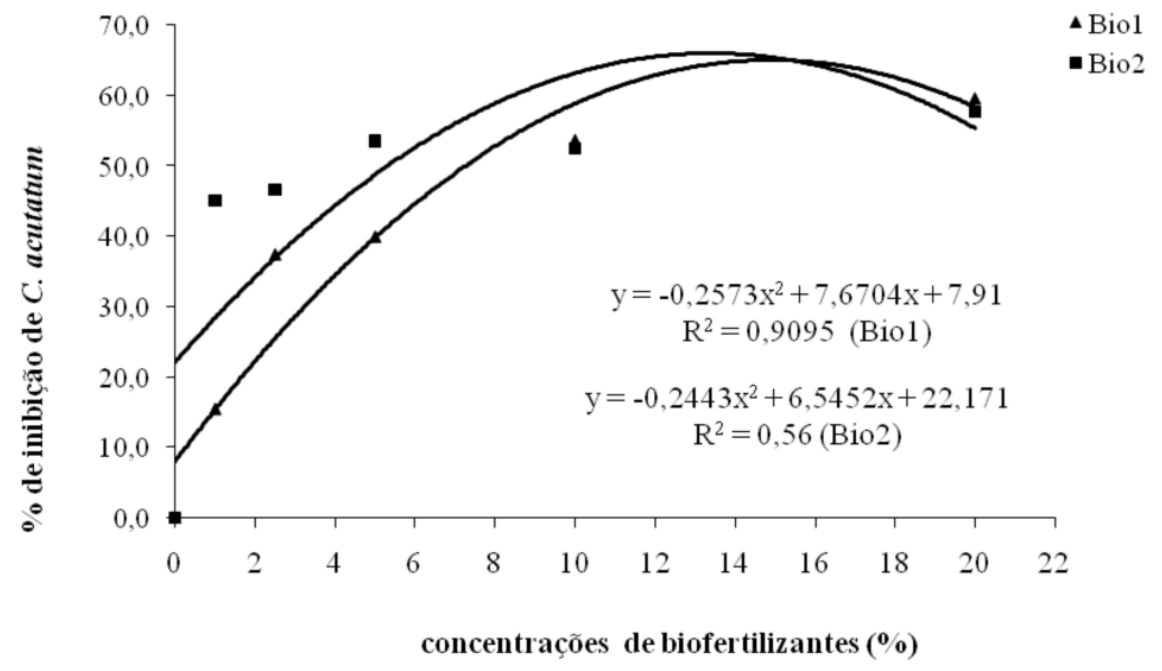

FIGURA 1 - Porcentagem de inibição da germinação de esporos de Colletotrichum acutatum submetidos ao tratamento com diferentes concentrações de biofetilizantes, em meio ágar-água, em relação à testemunha, após 16 horas de incubação a $25^{\circ} \mathrm{C}$. 
TABELA 1 - Porcentagem de inibição da germinação de esporos de Colletotrichum acutatum submetidos ao tratamento com Agentes de controle Biológico (ACBs), em meio ágar-água, em relação à testemunha, após 16 horas de incubação a $25^{\circ} \mathrm{C}$.

\begin{tabular}{|c|c|c|}
\hline Tratamentos & Esporos Germinados (\%) & Inibição da Germinação (\%) \\
\hline Testemunha & $77,42 \mathrm{a}^{(1)}$ & - \\
\hline B. subtilis (ACB-69) & $67,00 \mathrm{a}$ & 13,46 \\
\hline T. aureoviride (ACB-39) & $61,28 \mathrm{ab}$ & 20,85 \\
\hline ACBS $69+72+77$ & $44,28 \mathrm{bc}$ & 42,81 \\
\hline ACBs $69+37$ & $37,75 \quad c$ & 51,24 \\
\hline ACBs $37+69+14$ & 36,86 & 52,39 \\
\hline T. viride (ACB-14) & $35,43 \quad \mathrm{c}$ & 54,24 \\
\hline B. subtilis (ACB-77) & 33,71 & 56,46 \\
\hline B. subtilis (ACB-72) & $29,14 \mathrm{~cd}$ & 62,36 \\
\hline T. pseudokoningii (ACB-37) & 14,85 & 80,82 \\
\hline
\end{tabular}

${ }^{(1)}$ Médias seguidas pela mesma letra na coluna não diferem entre si, pelo teste de Tukey, a $5 \%$ de probabilidade.

TABELA 2 - Efeito de isolados de Bacillus subtilis e Trichoderma spp., combinados ou não com os biofertilizantes, na germinação de esporos de Colletotrichum acutatum.

\begin{tabular}{|c|c|c|}
\hline Tratamentos & Esporos Germinados (\%) & Inibição da Germinação (\%) \\
\hline Testemunha & $79,12 \mathrm{a}^{(2)}$ & - \\
\hline $\mathrm{ACB}-72+\mathrm{Biol}^{(1)}$ & $44,37 \mathrm{~b}$ & 43,92 \\
\hline $\mathrm{ACB}-77+\mathrm{Bio} 2$ & $40,75 \mathrm{bc}$ & 48,50 \\
\hline ACB-77 + Bio1 & $30,71 \mathrm{~cd}$ & 61,19 \\
\hline $\mathrm{ACB}-72+\mathrm{Bio} 2$ & 23,05 & 70,87 \\
\hline ACB-14 + Bio1 & 21,25 & 73,14 \\
\hline $\mathrm{ACB}-37+\mathrm{Bio} 2$ & 20,75 def & 73,77 \\
\hline $\mathrm{ACB}-14+\mathrm{Bio} 2$ & 19,75 & 75,04 \\
\hline Bio1 & 18,12 & 77,10 \\
\hline $\mathrm{ACB}-37+\mathrm{Bio} 1$ & 17,05 & 78,45 \\
\hline Bio2 & 13,00 & 83,57 \\
\hline
\end{tabular}

${ }^{(1)} \mathrm{ACBs} 72$ e 77 (B. subtilis); ACBs 14 e 37 (T. viride e T. pseudokoningii, respectivamente); Bio1 (Biofertilizante produzido sob condições anaeróbias, de acordo com Bettiol et al. (1998) e Bio 2 (Biofertilizante produzido sob condições aeróbias, misturando-se $50 \mathrm{~kg}$ de Microgeo $\left(200\right.$ litros de esterco de gado ). ${ }^{(2)}$ Médias seguidas pela mesma letra na coluna não diferem entre si, pelo teste de Tukey, a $5 \%$ de probabilidade. 
TABELA 3 - Porcentagem de inibição de esporos de Colletotrichum acutatum submetidos aos metabólitos termoestáveis, produzidos por Bacillus subtilis, em meio ágar-água, em relação à testemunha, após 16 horas de incubação a $25^{\circ} \mathrm{C}$.

\begin{tabular}{ccc}
\hline Tratamentos & Esporos Germinados (\%) & Inibição da Germinação (\%) \\
\hline Testemunha & $85,75 \mathrm{a}^{*}$ & - \\
ACB-72 & $79,05 \mathrm{a}$ & 7,81 \\
ACBs $72+77$ & 55,87 b & 34,85 \\
ACBs 69+AP3 & 51,75 b & 39,65 \\
ACBs 72+AP3 & 49,00 bc & 42,86 \\
ACB-AP3 & 37,37 cd & 56,42 \\
ACBs 69+72 & 34,37 de & 59,92 \\
ACBs 69+77 & 33,87 de & 60,50 \\
ACB-69 & 31,12 de & 63,71 \\
ACB-77 & 29,00 de & 66,18 \\
ACBs 72+69+77+AP3 & 22,75 e & 73,47 \\
\hline
\end{tabular}

*Médias seguidas pela mesma letra na coluna não diferem entre si, pelo teste de Tukey, a 5\% de probabilidade.

TABELA 4 - Porcentagem de pétalas com sintomas de Queda Prematura de Frutos Cítricos (QPFC), em flores destacadas de lima-ácida 'Tahiti' tratadas com Bacillus subtilis, 24 horas antes da inoculação com Colletotrichum acutatum.

\begin{tabular}{|c|c|c|}
\hline Tratamentos & Pétalas com Sintomas $(\%)$ & Controle da QPFC (\%) \\
\hline Testemunha & $68,01 \mathrm{a}^{(1)}$ & - \\
\hline ACB-63 & $66,98 \mathrm{a}$ & 1,51 \\
\hline ACB-64 & $51,67 \mathrm{ab}$ & 24,03 \\
\hline ACB-75 & $50,67 \mathrm{ab}$ & 25,50 \\
\hline ACB-71 & $49,50 \mathrm{ab}$ & 27,22 \\
\hline ACB-65 & $48,49 \mathrm{ab}$ & 28,70 \\
\hline ACB-70 & $46,08 \mathrm{ab}$ & 32,25 \\
\hline ACB-72 & $38,25 \mathrm{bc}$ & 43,76 \\
\hline $\mathrm{ACB}-73$ & $36,50 \mathrm{bc}$ & 46,33 \\
\hline ACB-67 & $28,89 \mathrm{bcd}$ & 57,52 \\
\hline ACB-66 & $14,64 \mathrm{~cd}$ & 78,47 \\
\hline ACB-68 & $14,42 \mathrm{~cd}$ & 78,80 \\
\hline ACB-69 & $11,83 \mathrm{~cd}$ & 82,61 \\
\hline ACB-76 & 5,75 & 91,54 \\
\hline ACB-74 & 5,21 & 92,34 \\
\hline ACB-77 & 1,90 & 97,21 \\
\hline
\end{tabular}

${ }^{(1)}$ Médias seguidas pela mesma letra na coluna não diferem, pelo teste de Tukey, a $5 \%$ de probabilidade. 
TABELA 5 - Número médio de frutos efetivos (NMFE), em plantas de laranjeira-'Pera-Rio', após o tratamento com Bacillus subtilis e biofertilizante.

\begin{tabular}{cc}
\hline Tratamentos & NMFE $^{(1)(2)}$ \\
\hline Bacillus subtilis & $35,12 \mathrm{a}$ \\
Biofertilizante & $32,46 \mathrm{a}$ \\
Testemunha & $16,08 \mathrm{~b}$
\end{tabular}

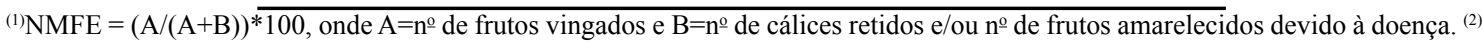
Médias seguidas pela mesma letra na coluna não diferem entre si, pelo teste de Tukey, a 5\% de probabilidade.

TABELA 6 - Número médio de frutos efetivos (NMFE), em plantas de laranjeira-'Pera-Rio', após tratamento com agentes de controle biológico e biofertilizantes.

\begin{tabular}{cc}
\hline Tratamentos & NMFE $^{(1)(2)}$ \\
\hline BioPiro $^{\circledR}$ & $80,10 \mathrm{a}$ \\
Bio 2+ACB14 & $73,10 \mathrm{ab}$ \\
ACB-72 & $69,20 \mathrm{ab}$ \\
ACB-69 & $63,63 \mathrm{ab}$ \\
Bio 2 & $59,87 \mathrm{ab}$ \\
Bio1 & $59,93 \mathrm{ab}$ \\
ACB-77 & $57,93 \mathrm{ab}$ \\
Testemunha & $47,44 \mathrm{~b}$ \\
Bio 2+ACB-37 & $47,00 \mathrm{~b}$ \\
Mistura (ACBs 69+72+77) & $46,27 \mathrm{~b}$
\end{tabular}

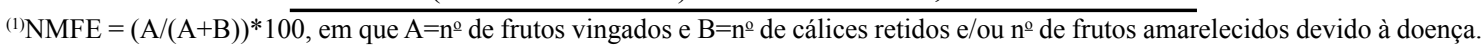
${ }^{(2)}$ Médias seguidas pela mesma letra na coluna não diferem entre si, pelo teste de Tukey, a 5\% de probabilidade.

\section{CONCLUSÕES}

Os agentes de controle biológico representados por B. subtilis e Trichoderma spp., assim como o emprego de biofertilizantes, isoladamente ou em combinação com ACBs, mostram-se como estratégias promissoras para o controle de C. acutatum, já que inibem a sua germinação conidial, suprimem a produção de sintomas em flores de lima-ácida 'Tahiti' destacadas e propiciam a obtenção de maior produtividade, representada pelo número médio de frutos efetivos.

\section{REFERÊNCIAS}

ARRAS, G.; ARRU, S. Mechanism of action of some microbial antagonists against fungal pathogens. Annali di Microbiologia ed Enzimologia, Milan, v.47, p.97-120, 1997.
BAKER, J.C.; STAVELY, J.R.; THOMAS, C.A.; SASSER, M.; Mac MACFALL, J.S. Inhibitory effect of Bacillus subtilis on Uromyces phaseoli and on development of rust pustules on bean leaves. Phytopathology, St. Paul, v.73, p.1148-1152, 1983.

BETTIOL, W.; KIMATI, H. Seleção de microrganismos antagônicos a Pyricularia oryzae Cav. para o controle do Brusone do arroz (Oryza sativa L.). Summa Phytopathologica, Botucatu, v.15, p. 257266, 1989.

BETTIOL, W.; KIMATI, H. Efeito de Bacillus subtilis sobre Pyricularia oryzae agente causal da brusone do arroz. Pesquisa Agropecuária Brasileira, Brasília, v.25, n.8, p.1165-1174, 1990.

BETTIOL, W.; SAITO, M.L.; BRANDÃO, M.S.B. Controle da ferrugem do cafeeiro com produtos à base de Bacillus subtilis. Summa Phytopathologica, Botucatu, v.20, n.2, p.119-122, 1994. 
BETTIOL, W.; TRATCH, R.; GALVÃO, J.A.H. Controle de doenças de plantas com biofertilizantes. Jaguariúna: EMBRAPA-CNPMA, 1998. p. 22.

BETTIOL, W.; VARZEA, V.M.P. Controle biológico da ferrugem (Hemileia vastatrix) do cafeeiro com Bacillus subtilis em condições controladas. Fitopatologia Brasileira, Brasília, v.17, n.1, p.91-95, 1992.

BROWN, A.E.; SREENIVASAPRASAD, S.; TIMMER, L.W. Molecular characterization of slow-growing orange and Key Lime anthracnose of Colletotrichum from citrus as C. acutatum. Phytopathology, St. Paul, v.86, n.5, p.523-527,1996.

CASTRO, C.M.; SANTOS, A.C.V.; AKIBA, F. Bacillus subtilis isolado do biofertilizante "Vairo" com ação fungistática e bacteriostática a alguns fitopatógenos. In: SIMPÓSIO DE CONTROLE BIOLÓGICO, 3., 1992. São Paulo. Anais... Jaguariúna: EMBRAPA-CNPDA, Jaguariúna, 1992. p.291.

COSTA, F. Efeito de agentes de controle biológico sobre $C$. acutatum, agente causal da flor-preta do morangueiro. 2001. Trabalho (Graduação em Agronomia) - Faculdade de Ciências Agrárias e Veterinárias, Universidade Estadual Paulista, Jaboticabal,. 2001

CUBETA, M.A.; HARTMAN, G.L.; SINCLAIR, J.B. Interaction between Bacillus subtilis and fungi associated with soybean seeds. Plant Disease, St. Paul, v.69, n.6, p.506-509, 1985.

DORNELLES, C.M.M. O problema da queda de frutos jovens de citros no Rio Grande do Sul. In: MESA-REDONDA PARA ESTUDO DA QUEDA DE FRUTOS JOVENS EM CÍTRUS, 1977, Taquari, p.3-6.

DUBOS, B.; JAILLOUX, F.; BULIT, J. Protection du vignoble contre la pourriture grise: les propriétes antagonises du Trichoderma a l'égard du Botrytis cinerea. Les Colloques de L'INTRA, Bordeaux, v.11, p.205-219, 1982.

ELAD, Y.; SHTIENBERG, D. Effect of compost water extracts on grey mould (Botrytis cinerea). Crop Protection, Amsterdan, v.13, p.109-114, 1994.

FAGAN, H.J. Postbloom fruit drop of citrus, a new disease of citrus associated with a form of Colletotichum acutatum. Annual Applied Biology, London, v.91, n.1, p.13-20, 1979.
FEICHTENBERGER, E. Queda de frutos jovens em citros. Laranja, Cordeirópolis, v.12, p.513-521, 1991.

FERREIRA, J.H.S.; MATTHEE, F.N.; THOMAS, A.C. Biological control of Eutypa lata on grapevine by an antagonistic strain of Bacillus subtilis. Phytopathology, St. Paul, v.81, p.283-287, 1991.

GOES, A. de. Queda prematura de frutos cítricos: Caracterização do agente causal, Colletotricum gloeosporioides Penz. (Sensu Arx, 1957), e controle da doença. 1995. 143 f. Tese (Doutorado em Fitopatologia) - Escola Superior de Agricultura Luiz de Queiroz, Universidade de São Paulo, Piracicaba, 1995.

KALITA, P.; BORA, L.C.; BHAGABATI, K.N. Phylloplane microflora of citrus and their role in management of citrus canker. Indian Phytopathology, New Delhi, v 49, n.3, p. 234-237, 1996.

KORSTEN, L.; DE VILLIERS, E.E.; WEHNER, F.C.; KOTZÉ, J.M. Field sprays of Bacillus subtilis and fungicides for control of preharvest fruit diseases of avocado in South Africa. Plant Disease, St. Paul, v. 81, p.455-459, 1997.

KUPPER, K.C.; BETTIOL, W.; GOES, A. de; SOUZA, P.S. de; BELLOTTE, J.A.M. Biofertilizer for control of Guignardia citricarpa, the causal agent of citrus black spot. Crop Protection, Amsterdan, v. 25, p.569-573, 2006.

KUPPER,K.C.; GIMENES-FERNANDES, N. Isolamento e seleção de Bacillus spp. para o controle de Colletotrichum acutatum em flores destacadas de lima-ácida 'Tahiti'. Summa Phytopathologica, Botucatu, v. 28, n.3, p. 292-295, 2002.

KUPPER, K.C.; GIMENES-FERNANDES, N.; GOES, A. de. Controle biológico de Colletotrichum acutatum, agente causal da queda prematura dos frutos cítricos. Fitopatologia Brasileira, Brasília, v. 28, n.3, p. $251-257,2003$

MCQUILKEN, M.P.; WHIPPS, J.M.; LYNCH, J.M. Effects of water extracts of a composted manurestraw mixture on the plant pathogen Botrytis cinerea. World Journal Microbiology \& Biotechnology, Netherlands, v.10, p.20-26, 1994. 
MELO, I.S. Agentes microbianos de controle de fungos fitopatogênicos. In: MELO, I.S.; AZEVEDO, J.L. Controle biológico. Jaguariúna: EMBRAPA, 1998.

MORETTO, K.C.K.; GIMENES-FERNANDES, N.; SANTOS, J.M. dos. Influence of Trichoderma spp. on Colletotrichum acutatum mycelial growth and morphology and on infection of 'Tahiti' lime detached flowers. Summa Phytopathologica, Botucatu, v.27, n.4, p.357-364, 2001.

SÃO PAULO. Secretaria de Estado de Agricultura, Pecuária E Abastecimento De São Paulo. Previsão da safra agrícola de laranja do Estado de São Paulo, ano agrícola 2007/2008: $1^{\circ}$ levantamento, maio de 2008. Disponível em: <ftp://ftp.sp.gov.br/ ftpiea/mercado/laranja0508.pdf $>$. Acesso em: 11 set. 2008.

SONODA, R.M.; GUO, Z. Effect of spray applications of Bacillus subtilis on postbloom drop of citrus. Phytopathology, St. Paul, v.86, p.S52, 1996.
TRATCH, R.; BETTIOL, W. Efeito de biofertilizantes sobre o crescimento micelial e a germinação de esporos de alguns fungos fitopatogênicos. Pesquisa Agropecuária Brasileira, Brasília, v. 32, p.11311139, 1997.

WELTZIEN, H.C. Some effects of composted organic materials on plant health. Agriculture, Ecosystems and Environment, Amsterdan, v. 27, p.439-446, 1989.

YOHALEM, D.S.; NORDHEIM, E.V.; ANDREWS, J.H. The effect of water extracts of spent mushroom compost on apple scab in the field. Phytopathology, St. Paul, v. 86, p. 914-922, 1996.

ZHANG, W.; DICK, W.A.; HOITINK, H.A.J. Compost-induced systemic acquired resitance in cucumber to Pythium root rot and anthracnose. Phytopathology, St. Paul, v. 86, p. 1066-1070, 1996. 